Volume 2

Issue 4 -- Integrative Medicine

Article 2

$11-20-2015$

\title{
In Vitro Growth Suppression of Renal Carcinoma Cells by Curcumin
}

Santhi D. Konduri

Madhavi Latha Yadav Bangaru

Phu Thanh Do

Shenglin Chen

Jeffrey Woodliff

Sanjay Kansra

Follow this and additional works at: https://aah.org/jpcrr

Part of the Cells Commons, Life Sciences Commons, Neoplasms Commons, and the Oncology

Commons

\section{Recommended Citation}

Konduri SD, Bangaru ML, Do P, Chen S, Woodliff J, Kansra S. In vitro growth suppression of renal carcinoma cells by curcumin. J Patient Cent Res Rev. 2015;2:156-164. doi: 10.17294/2330-0698.1197

Published quarterly by Midwest-based health system Advocate Aurora Health and indexed in PubMed Central, the Journal of Patient-Centered Research and Reviews (JPCRR) is an open access, peer-reviewed medical journal focused on disseminating scholarly works devoted to improving patient-centered care practices, health outcomes, and the patient experience. 


\title{
In Vitro Growth Suppression of Renal Carcinoma Cells by Curcumin
}

\author{
Santhi D. Konduri, PhD, ${ }^{1 *}$ Madhavi Latha Yadav Bangaru, PhD, ${ }^{2 *}$ Phu Thanh $\mathrm{Do}, \mathrm{PhD},{ }^{3 *}$ \\ Shenglin Chen, PhD, ${ }^{2}$ Jeffrey Woodliff, PhD, ${ }^{3}$ Sanjay Kansra, $\mathrm{PhD}{ }^{1,2,3,4}$ \\ ${ }^{1}$ Aurora Research Institute, Aurora Health Care, Milwaukee, WI \\ ${ }^{2}$ Department of Medicine, Medical College of Wisconsin, Milwaukee, WI \\ ${ }^{3}$ Department of Pediatrics, Medical College of Wisconsin, Milwaukee, WI \\ ${ }^{4}$ Department of Pharmacology, Medical College of Wisconsin, Milwaukee, WI
}

Purpose Malignant clear cell renal carcinoma (ccRCC) is an aggressive tumor highly resistant to chemotherapy and radiation. Current therapeutic approaches to management of ccRCC have not significantly improved patient survival, therefore novel therapies are needed. Activated NFKB and STAT3 expression is associated with ccRCC pathogenesis. The dietary polyphenol curcumin is a well-documented antitumor agent and a known inhibitor of NFKB and STAT3 activation. Given the lack of effective therapies that block ccRCC progression, our objective was to examine whether curcumin could suppress the growth and migration of CCRCC cells, and whether this suppression was mediated via inhibition of NFKB and STAT3 activity.

Methods Human ccRCC cell lines (769-p, 786-o, Caki-1, ACHN and A-498 cells) were exposed to curcumin to assess the impact of curcumin on ccRCC cell viability. Colony formation assay was used to assess the effect of curcumin on ccRCC cell renewal capability. Effect of curcumin on apoptosis was determined by annexin $\mathrm{V}$ binding and mitochondrial membrane depolarization assays. The anti-migratory effect of curcumin on cCRCC cells was assessed using the wound healing assay. Effect of curcumin on NFKB and STAT3 phosphorylation in 769-p cells was determined by western blot analysis.

Results In ccRCC cells, curcumin decreased cell proliferation and cell viability, abolished clonogenic property, induced apoptosis and blocked cellular migration. The growth suppressive and pro-apoptotic effects of curcumin were accompanied by decreased phosphorylation of NFKB and STAT3.

Conclusions The ability of curcumin to induce apoptosis and inhibit migration of ccRCC cells justifies additional mechanistic and preclinical studies that examine the effect of curcumin or other NFKB and STAT3 inhibitors as potential suppressors of ccRCC tumorigenesis. (J Patient-Centered Res Rev. 2015;2:156-164.)

Keywords

curcumin, dietary polyphenol, apoptosis, renal carcinoma

The incidence of malignant clear cell renal carcinoma (ccRCC) has risen in the last two decades, particularly in African Americans, Hispanics and women. The standard cytokine-based therapy with interferon- $\alpha$ (IFN- $\alpha$ ) or interleukin-2 has not been effective at suppressing ccRCC growth (5-year survival less than $10 \%$ ), and toxicity is common. ${ }^{1}$ Although the use

\footnotetext{
*Drs. Konduri, Bangaru and Do contributed equally to this report.

Correspondence: Sanjay Kansra, PhD, Aurora Research Institute, 960 N. 12th Street, Suite \#4120, Milwaukee, WI, 53233, T: 414-219-5393, F: 414-219-5381,

Email: sanjay.kansra@aurora.org
}

of targeted therapies in the clinical management of ccRCC has provided benefits in terms of prolonging progression-free survival, eventually patients develop resistance and disease recurs. ${ }^{2-4}$ Therefore, more effective and less toxic therapeutic agents are needed.

At the molecular level, disruption of several signaling pathways has been shown to contribute to the development and progression of ccRCC. Mutations in the tumor suppressor von Hippel-Lindau gene ( $V H L)$ are common in ccRCC. ${ }^{5,6}$ The protein product of $V H L$, pVHL, functions to suppress transcriptional activity of hypoxia-inducible factor (HIF)- $1 \alpha$ and HIF-2 $\alpha$. HIFs regulate the expression of genes involved in cell survival and angiogenesis (transforming growth 
factor $\alpha$, platelet-derived growth factor and vascular endothelial growth factor). ${ }^{7}$ Thus, the consequence of an inactive pVHL is increased growth factor expression and growth factor receptor-mediated signaling. The increase in receptor-mediated signaling leads to the activation of transcription factors, including NF $\kappa B$ and STAT3, which have well-defined roles in promoting tumor growth.

Increased NF $\kappa \mathrm{B}$ activity stimulates the expression of gene proteins (bcl-2, MMP-2 and MMP-9) critical to tumor survival and invasion. Indeed, increased NFKB activity has been correlated with ccRCC progression, and upregulation of the prosurvival protein bcl-2 in human ccRCC is a common occurrence. ${ }^{8,9}$ The highly metastatic and invasive nature of ccRCC has been attributed to increased expression of matrix metalloproteinases (e.g. MMP-2 and MMP-9) that promote the disruption of extracellular matrices. Expression of bcl-2, MMP-2 and MMP-9 is regulated by NFאB.

Constitutively activated STAT3 is associated with tumor progression, angiogenesis and development of chemotherapy/radiotherapy resistance. ${ }^{10-12}$ These effects of STAT3 are believed to be mediated through upregulation of cyclins, vascular endothelial growth factor and bcl-2. ${ }^{13}$ Increased STAT3 expression has been detected in human ccRCC, and STAT3 was shown to promote interleukin-6-mediated proliferation of ccRCC cells. ${ }^{14,15}$

$\mathrm{NF} \kappa \mathrm{B}$ and STAT3 are activated by HIF-induced growth factors and play critical roles in promoting ccRCC tumorigenesis. To the best of our knowledge, successful pharmacological targeting aimed at suppressing HIF-mediated transcription in ccRCC has not been achieved. For this study we investigated whether the dietary polyphenol curcumin, a known suppressor of $\mathrm{NF} \kappa \mathrm{B}$ and STAT3 transcriptional activity, ${ }^{16,17}$ would be effective at suppressing ccRCC tumor cell growth.

\section{MATERIALS AND METHODS Chemicals and Reagents}

Curcumin was purchased from LTK Laboratories (St. Paul, MN) and Sigma-Aldrich (St. Louis, MO). 786-o, Caki-1, ACHN and A-498 cells were purchased from American Type Culture Collection (ATCC) (Manassas, VA). 769-p cells used in this study were either provided by Dr. A. Sorokin (Medical College of Wisconsin, Milwaukee, WI) or purchased from ATCC. Phospho-p65 NFкB (S536), total-p65 NFkB, phospho-STAT3 (S727) and total-STAT3 antibodies were purchased from Cell Signaling Technology (Danvers, MA).

\section{Cell Culture and Assessment of Cell Viability} 769-p, 786-o, Caki-1, ACHN and A-498 cells were maintained in complete growth medium containing $10 \%$ fetal bovine serum (FBS). Medium was replaced every 2-3 days and subculturing done as required. To assess cell viability, equal number of cells were seeded in a 96-well plate in complete growth medium. After an overnight incubation at $37^{\circ} \mathrm{C}$, cells were exposed to vehicle or curcumin in medium containing $0.5 \% \mathrm{FBS}$. In experiments that evaluated the dose-dependency of curcumin on ccRCC cell viability or on DNA synthesis, indicated cell lines were exposed to curcumin $(0-200 \mu \mathrm{M})$ for 72 hours. In experiments that examined the time-course of curcumin-induced suppression of ccRCC cell viability, 769-p cells were exposed to curcumin $(0,5$ or $50 \mu \mathrm{M})$ for 1,2 or 3 days. After treatment, cell viability was quantitated by using either the colorimetric MTT assay or the Cell Titer-Glo ${ }^{\circledR}$ Luminescent Cell Viability Assay (Promega, Madison, WI) as previously described. ${ }^{18,19}$ DNA synthesis was measured by determining bromodeoxyuridine (BrdU) incorporation into DNA as previously described. ${ }^{20}$

\section{Colony Formation Assays}

Colony formation ability of 769-p cells was determined as previously described. ${ }^{18}$ To briefly summarize, 769-p cells growing in log phase were seeded at a density of 3,000 cells/well in a 6-well plate in complete growth medium. Cells were allowed to adhere for an overnight period, following which the medium was replaced with complete medium containing curcumin $(0,5,20,50$, 100 or $200 \mu \mathrm{M}$ ). Cells were cultured for approximately 2 weeks, with a medium change (containing fresh vehicle or curcumin) performed every 4-5 days. Crystal violet was used to stain and visualize the colonies.

\section{Annexin V Staining Assays}

769 -p cells were treated with curcumin $(0,5$ or $50 \mu \mathrm{M})$ for 24 hours. After treatment, cells were washed with phosphate-buffered saline and stained with annexin V-FITC and propidium iodide. Subsequent flow cytometry was performed as previously described. ${ }^{18}$ 


\section{Western Blotting}

769 -p cells were treated with curcumin $(0,5,20$ or $50 \mu \mathrm{M}$ ) for 30 minutes. After treatments, protein content was determined in the cellular lysates and an equal amount of protein subjected to electrophoresis, followed by western blotting with the indicated antibodies as previously described. ${ }^{18}$ The pixel intensities of the western blot bands (p-p65 NFкB, t-p65 NFkB, p-STAT3 and t-STAT3) were quantitated using the intensity plot and area calculation functions of the ImageJ program available from the National Institutes of Health (http:// rsbweb.nih.gov/ij/). After normalization to the band intensities of total proteins (t-p65 NFאB and t-STAT3), p-p65 NFkB and p-STAT3 protein expressions were calculated. The control (vehicle-treated sample) was assigned an arbitrary value of 1 , and fold change in the curcumin-treated groups was calculated.

\section{Mitochondrial Membrane Depolarization Assays}

769 -p cells were treated with curcumin $(0,5$ or $50 \mu \mathrm{M})$ for 24 hours. Cells were washed, stained with JC-1 dye, and then analyzed by flow cytometry, according to the manufacturer's protocol (Cell Technology, Fremont, CA) as previously described. ${ }^{18}$

\section{Wound Healing Assay}

Wound healing assay for migration was performed as previously described. ${ }^{21}$ Briefly, 769-p cells were grown to monolayer confluency in 6-well plates. A sterile p200 pipette tip was used to inflict a scratch wound. Cellular debris was removed by washing, and subsequently phase contrast microscopy was used to capture an image of the wound. Impact of 24 -hour curcumin treatment $(0,5$ or $50 \mu \mathrm{M})$ on wound closure in 769-p cells was assessed.

\section{RESULTS}

\section{Curcumin Inhibits ccRCC Cell Proliferation and Viability}

We initially investigated whether curcumin was effective in suppressing the growth of ccRCC cell lines. To address this, we evaluated the concentration-dependent effect of curcumin on cell viability in a panel of human ccRCC cell lines. 769-p, 786-o, Caki-1, ACHN and A-498 cells were treated with curcumin and cell viability assessed. Our data demonstrated that in all five human ccRCC cell lines, curcumin was able to significantly $(\mathrm{P}<0.05)$ suppress cell viability (Figure 1), with maximal ( $>90 \%$ ) growth suppression in the concentration range of 50-200 $\mu \mathrm{M}$. In 769-p cells significant $(\mathrm{P}<0.05)$ growth suppression was also detected at a lower concentration $(20 \mu \mathrm{M})$. Although of a small magnitude $(\sim 13 \%)$, we did detect a significant $(\mathrm{P}<0.05)$ growth stimulation in A-498 cells in response to a lower concentration $(10 \mu \mathrm{M})$ of curcumin.

It has been reported that genetic or epigenetic variations in $V H L$ can be detected in approximately $90 \%$ of human RCC cases. ${ }^{22}$ Given that 769-p cells do not express $V H L$ mRNA, we used this VHL-deficient system for our subsequent studies that examined the mechanism by which curcumin suppressed ccRCC cell growth. ${ }^{23}$
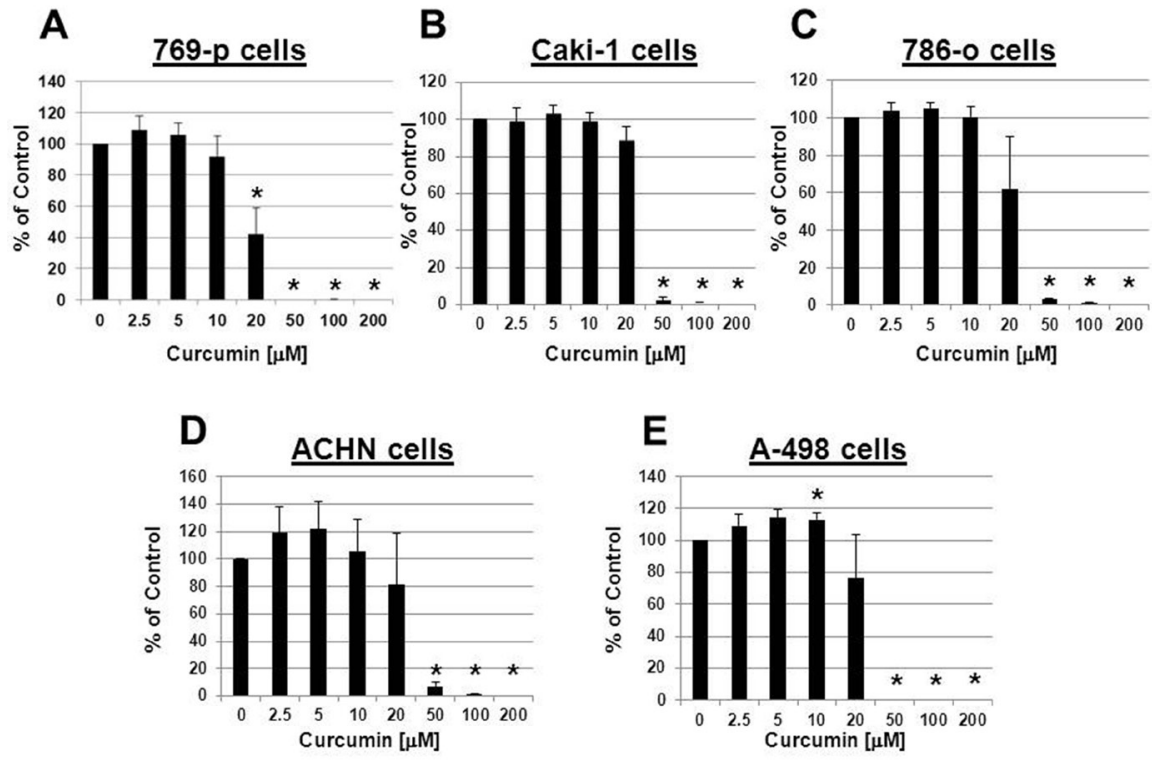

Figure 1. Curcumin inhibits ccRCC cell proliferation and viability. 769-p cells (A), Caki-1 cells (B), 786-o cells (C), ACHN cells (D) and A-498 cells (E) were treated with the indicated concentrations of curcumin. After 3 days cell viability was detected using the Cell Titer-Glo Luminescent Cell Viability Assay. Data were calculated as percentage of vehicle control, and are the mean ( \pm standard error of the mean, SEM) of three independent experiments. Asterisks (*) designate a significant difference $(P<0.05)$ from control values. 
We next examined the kinetics of curcumin-induced inhibition of 769-p cell proliferation. Our data showed that compared to vehicle treatment, $5 \mu \mathrm{M}$ curcumin had no significant effect on 769-p cell proliferation at either the early time points or later time points (Figure 2A). On the other hand $50 \mu \mathrm{M}$ curcumin had a significant inhibitory effect on cell proliferation as early as 1 day, and this inhibitory effect persisted up to 3 days.

A

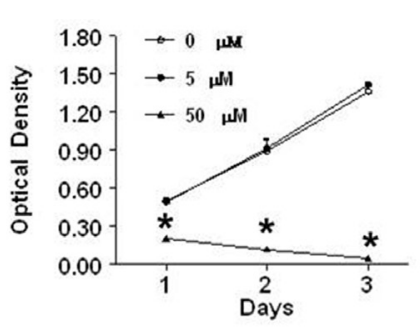

C

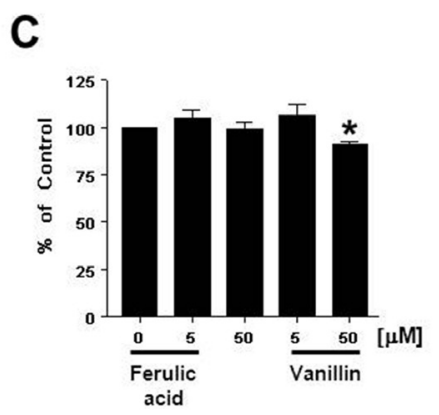

Figure 2. Curcumin inhibits $c c R C C$ cell proliferation in a time-dependent manner. A: 769-p cells were treated with vehicle control, or 5 or $50 \mu M$ curcumin for the indicated times, and cell viability was assessed. Data are presented as optical density and are the mean $( \pm$ SEM) of at least three independent determinations. Data are representative of two separate experiments yielding similar results. Asterisks $\left(^{*}\right)$ designate a significant difference $(P<0.05)$ from day 1 control. B: 769-p cells were treated with indicated concentrations of curcumin. After 3 days, proliferation was assessed by the BrdU incorporation assay. Data are presented as optical density and are the mean ( \pm SEM) of at least three independent determinations. Data are representative of two separate experiments yielding similar results. Asterisks $\left(^{*}\right)$ designate a significant difference $(P<0.05)$ from control values. $C$ : $769-p$ cells were treated with indicated concentrations of ferulic acid or vanillin, and after 2 days cell proliferation was assessed by the MTT assay. Data are presented as percentage of control and are the mean ( \pm SEM) of three independent experiments. The asterisk $\left(^{*}\right)$ designates a significant difference $(P<0.05)$ from control value.
To confirm that the growth inhibition detected in the cell viability assays was due to decreased DNA synthesis, we examined the effect of curcumin on BrdU incorporation in 769-p cells. A significant $(\mathrm{P}<0.05)$ inhibition of cell proliferation was detected with $20 \mu \mathrm{M}$ curcumin, and maximal suppression of cell proliferation was detected with 100-200 $\mu \mathrm{M}$ curcumin (Figure 2B).

Curcumin undergoes degradation in serum-depleted cell culture media, resulting in the formation of trans-6-(4'-hydroxy-3'-methoxyphenyl)-2,4-dioxo-5hexenal, ferulic acid, feruloyl methane and vanillin. ${ }^{24}$ Both ferulic acid and vanillin have been reported to mediate the antioxidant activity of curcumin..$^{25-28}$ To address the question of whether the growth suppressive effects of curcumin were mediated by the degradation products of curcumin, 769-p cells were treated with the indicated concentration of ferulic acid and vanillin, and cell proliferation determined after 2 days. Our data showed that $50 \mu \mathrm{M}$ ferulic acid had no significant growth suppression of 769-p cells (Figure $2 \mathrm{C})$. Although $50 \mu \mathrm{M}$ vanillin did suppress 769 -p cell proliferation $(<10 \%)$, it was approximately ninefold less effective than curcumin $(50 \mu \mathrm{M})$ at suppressing growth of 769-p cells.

\section{Curcumin Blocks Colony Formation Ability, Induces Apoptosis and Blocks Migration of ccRCC Cells}

Next, we questioned whether curcumin had any effect on the colony formation ability of 769-p cells. 769-p cells were seeded in medium containing 10\% FBS and allowed to adhere for 24 hours. The medium was then replaced with fresh medium containing $10 \%$ FBS together with the indicated concentration of curcumin, and colony formation was monitored over the ensuing 2 weeks. We observed that 769-p cells have a robust ability to form colonies and that this is abolished by curcumin in a concentration-dependent manner, with a substantial decrease in the number of 769-p cell colonies detected in presence of $5 \mu \mathrm{M}$ curcumin (Figure 3A). At higher concentrations of curcumin $(20-200 \mu \mathrm{M})$ the ability of 769-p cells to form colonies was completely ablated. Therefore, we questioned whether curcumin would induce apoptosis in ccRCC cells. To test this, 769-p cells were treated with the indicated concentrations of curcumin for 24 hours, washed, and incubated with JC-1 dye (a mitochondria-specific dual fluorescence probe) per manufacturer instructions (Cell Technologies). 
A

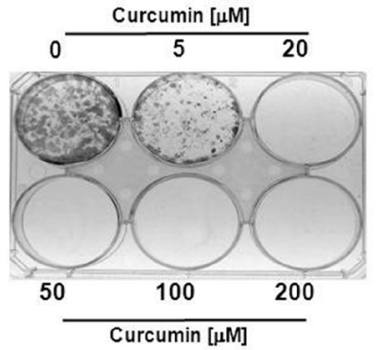

B

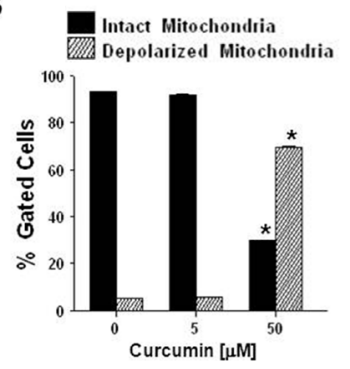

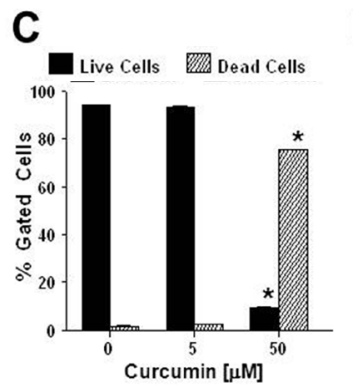

D

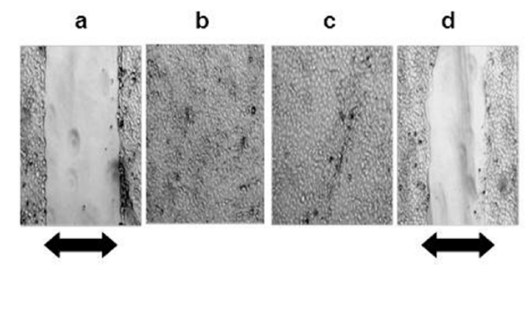

Figure 3. Curcumin blocks colony formation ability, induces apoptosis and blocks migration of ccRCC cells. A: 769-p cells were cultured in medium containing (0-200 $\mu \mathrm{M})$ curcumin, and colony formation was assessed after approximately 2 weeks by crystal violet staining. Data shown are from a single experiment that was representative of three similar experiments yielding similar results. B: 769-p cells were treated with indicated concentration of curcumin for 24 hours, and cells were washed and labeled with JC-1 dye. Decreased red and increased green fluorescence intensities were measured by flow cytometry. Quantitative changes in percentage of gated cells are presented as the mean $( \pm$ SEM) of three independent determinations. Data are from a single experiment that was representative of two independent experiments. Asterisks $\left(^{*}\right)$ designate a significant difference $(P<0.05)$ from control values. C: $769-p$ cells were treated with indicated concentrations of curcumin for 24 hours, subjected to annexin V-FITC and propidium iodide staining, and analyzed by flow cytometry. Live/dead cell ratios were calculated. Data are presented as percentage of gated cells and are the mean ( \pm SEM) of three independent determinations. Data are from a single experiment that is representative of two independent experiments. Asterisks $\left(^{*}\right)$ designate a significant difference $(P<0.05)$ from control values. $\boldsymbol{D}$ : After forming a monolayer, 769-p cells were serum starved from 24-48 hours, following which a scratch wound was inflicted by using a sterile p200 pipette tip. Cells were then incubated in medium containing fetal bovine serum (FBS), either in the presence of vehicle (control) or curcumin 5 and $50 \mu M$, for 24 hours. Bright field microscopy was used to examine the effect of curcumin on FBS-induced cell migration. Data shown are from a single experiment and representative of three independent experiments.

In vehicle- and $5 \mu \mathrm{M}$ curcumin-treated cells, 93.31\% and $92.01 \%$ of the cells were detected with intact mitochondrial membranes, respectively. However, in $50 \mu \mathrm{M}$ curcumin-treated cells, only $29.86 \%$ of cells presented intact mitochondrial membranes while $69.64 \%$ of the cell population presented with disruptions in the mitochondrial membrane (Figure 3B), indicating increased mitochondrial membrane depolarization.

To examine whether the increase in mitochondrial membrane depolarization would lead to increased cell death, 769-p cells were treated with the indicated concentrations of curcumin for 24 hours, and following trypsinization, annexin V-FITC binding and propidium iodide staining were analyzed by flow cytometry. Our results showed that in vehicle- and $5 \mu \mathrm{M}$ curcumintreated cells, $1.74 \%$ and $2.29 \%$ of cells, respectively, underwent apoptosis (Figure 3C). However, treatment with $50 \mu \mathrm{M}$ curcumin resulted in $75.49 \%$ of cells undergoing cell death.

Since ccRCC tumors are highly metastatic, we questioned whether curcumin would block migration of ccRCC cells. To test this, 769-p cells were grown to monolayer confluence and a scratch wound was inflicted. Cells were incubated overnight in FBS-containing medium together with either vehicle or curcumin. Our data showed that in both vehicle- and $5 \mu \mathrm{M}$ curcumin-treated cells, wound closure was complete (Figure 3D). However, $50 \mu \mathrm{M}$ curcumin significantly inhibited the migration of 769-p cells, as evidenced by lack of wound closure.

\section{Curcumin Decreases Phosphorylation of NFKB and STAT3 in ccRCC Cells}

Given the important role of NFKB and STAT3 in ccRCC pathogenesis, and since curcumin has been shown to suppress NFkB and STAT3 transcriptional activity, we questioned whether the ability of curcumin to induce apoptosis in ccRCC cells is accompanied with decreased NFkB and STAT3 activation. Because transcriptional activity of NFKB and STAT3 is positively regulated by phosphorylation, the impact of curcumin on the phosphorylation status of p65 NFKB and STAT3 was examined by western blotting with antibodies that specifically detect either the phosphorylated or total form of $\mathrm{p} 65 \mathrm{NF} \kappa \mathrm{B}$ and STAT3. Our data demonstrated 
that curcumin significantly $(\mathrm{P}<0.05)$ decreased phosphorylation of p65 NFkB (S536) by $27.18 \%$ and $48.71 \%$ at concentrations of 20 and $50 \mu \mathrm{M}$, respectively (Figure 4A, 4B). In addition, 20 and $50 \mu \mathrm{M}$ curcumin significantly $(\mathrm{P}<0.05) \quad$ decreased STAT3 $\quad(\mathrm{S} 727)$ phosphorylation in 769 -p cells by $31.14 \%$ and $48.76 \%$, respectively (Figure 4C, 4D). The observed decrease in the phosphorylated forms of $\mathrm{p} 65 \mathrm{NF} \kappa \mathrm{B}$ and STAT3 were not due to an effect of curcumin on the expression levels of p65 NFkB and STAT3 (Figure 4A, 4C).

\section{DISCUSSION}

Both in the United States and worldwide, the incidence of ccRCC and ccRCC-related mortality has increased over the past decade. The National Cancer Institute reports that approximately 54,000 new cases of renal cancer are diagnosed and approximately 13,000 deaths by renal cancer occur annually. Although ccRCC is highly resistant to chemotherapy/radiotherapy, a better understanding of the biology of ccRCC has led to the identification of several signaling pathways currently being examined as potential targets. It is now wellestablished that constitutively active STAT3 and NFKB participate in ccRCC pathogenesis. ${ }^{914}$ Thus, suppression of STAT3 and NFKB provides a novel therapeutic approach to suppressing ccRCC cell proliferation. Given the lack of effective therapies for ccRCC, and the welldocumented ability of the dietary polyphenol curcumin to suppress STAT3- and NFkB-mediated signaling, we examined whether ccRCC tumor suppression could be achieved with curcumin. It is also of interest to note that the age-adjusted incidence of kidney cancer in the United States is the highest in the world and approximately six times greater than rates in Asian countries where curcumin is regularly consumed through diet. Our in vitro study reveals that curcumin is effective at inducing apoptosis and suppressing migration of ccRCC cells.

In vitro characterization of the growth suppressive effects of curcumin in ccRCC cells revealed that curcumin, in a concentration- and time-dependent manner, suppressed 769-p cell viability and colony formation ability, induced apoptosis and blocked migration. We confirmed that the growth suppressive effect of curcumin was not cell typespecific, as in addition to the 769-p cells, curcumininduced growth suppression was detected in a panel of human ccRCC cell lines, including Caki-1, 786-o, ACHN and A-498 cells. We also examined the ability of curcumin to suppress the growth of RENCA (mouse renal carcinoma cells) and observed a similar growth suppressive pattern (data not shown). Of particular significance is the ability of curcumin to suppress the growth of IFN- $\alpha$-resistant 786-o cells. ${ }^{29}$ Our future studies will examine whether curcumin sensitizes IFN- $\alpha$-resistant ccRCC cells to IFN- $\alpha$-induced growth suppression.

We next questioned whether curcumin would decrease viability of normal renal proximal epithelial tubule cells. We observed that curcumin failed to induce apoptosis in cultured normal rat renal tubular epithelial cells (data not shown). Our observations are consistent with both in vitro and in vivo studies demonstrating a protective effect of curcumin on renal tubular epithelial cells. ${ }^{30,31}$ Taken together, our data clearly showed that curcumin could be an effective growth suppressor of ccRCC cells.
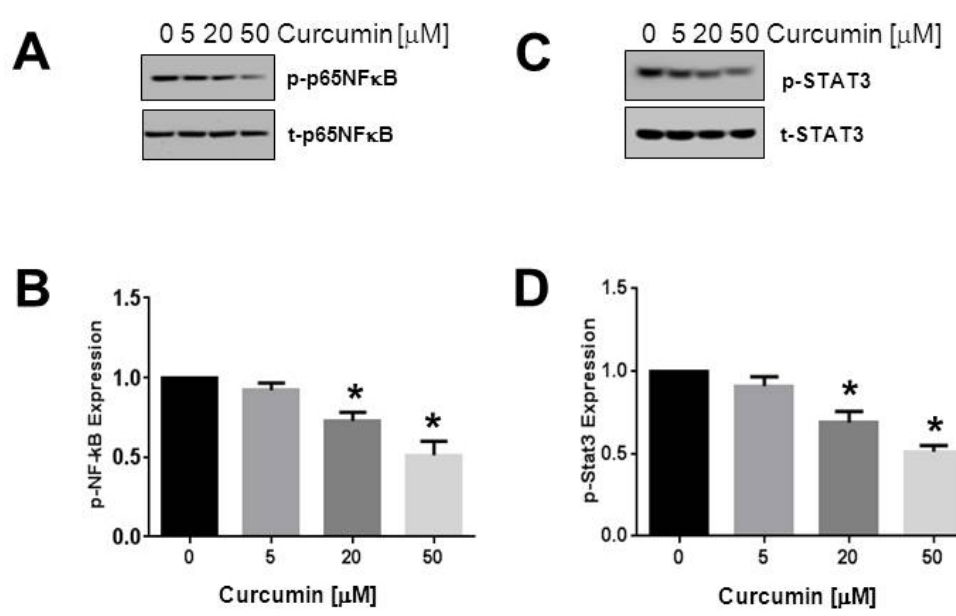

Figure 4. Curcumin decreases phosphorylation and transcriptional activity of NFKB and STAT3 in ccRCC cells. 769-p cells were treated with the indicated concentrations of curcumin for 30 minutes, and cell lysates were subjected to western blotting with anti-phospho p65 NFKB antibody $(\boldsymbol{A}$, top) and anti-total p65 NFKB antibody (A, bottom), or antiphospho STAT3 antibody (C, top) and anti-total STAT3 antibody (C, bottom). Data presented are from a single experiment and representative of three independent experiments. Western blots from all three experiments were quantified as described in the text. Fold change in expression of $p-p 65 N F K B$ (B) and p-STAT3 (D) from control (0 $\mu M$ curcumin) was determined. Data are the mean ( \pm SEM) of three independent experiments. Asterisks $\left({ }^{*}\right)$ designate a significant difference $(P<0.05)$ from control values. 
In most cases metastasis has already occurred when ccRCC is diagnosed. Therefore, the ability of curcumin to block cell migration of ccRCC cells was examined. Our wound healing assay data showed that curcumin was effective at blocking serum-induced wound closure.

Since degraded curcumin is known to yield dietary ferulates, especially in buffered medium and serumfree medium, we questioned whether the growth suppressive effects of curcumin we observed were due to the generation of ferulic acid and vanillin. However, because $50 \mu \mathrm{M}$ ferulic acid had no significant growth suppressive effect on 769-p cell viability and vanillin's modest growth suppressive effect on 769-p cell viability was approximately nine times less than curcumin at an equimolar concentration, we concluded that the growth suppressive effect of curcumin on ccRCC cell viability is not mediated by its degradation products, suggesting a direct effect of free curcumin. Our conclusion would be consistent with a response to a query raised from a recent article that described the antitumor effects of curcumin in pancreatic cancer patients. ${ }^{32}$ In their rebuttal the authors demonstrated that the suppressive effect of curcumin on tumor necrosis factor- $\alpha$-activated NFKB in human myeloid cells is not mediated by dietary ferulates, as both ferulic acid and vanillin failed to block NFKB activation by this protein.

Phosphorylation of the $\mathrm{p} 65$ subunit of NFkB regulates the DNA binding and transcriptional activity of NFkB. ${ }^{33}$ Likewise, in melanocytic cells, constitutively phosphorylated STAT3 has been shown to accumulate in the nucleus and promote cell survival. ${ }^{34}$ In examining the impact of curcumin on NFKB- and STAT3-mediated transcription in ccRCC cells, we found there is a robust expression of constitutively phosphorylated $\mathrm{p} 65$ NFkB and STAT3 in 769-p cells. Further, when 769-p cells are exposed to curcumin, a rapid decrease in the phosphorylation of transcription factors p65 NFkB and STAT3 was observed. Although our data clearly showed that curcumin decreases STAT3 and NFkB phosphorylation, the mechanism of this suppression in ccRCC cells remains to be determined. One of the key kinases that phosphorylate p65 NFאB is IKK $\alpha$, which phosphorylates p $65 \mathrm{NF} \kappa \mathrm{B}$ on serine $536 .{ }^{35}$ In multiple myeloma cells, curcumin inhibited constitutively activated IKK. ${ }^{36}$ It is possible the observed decrease in p65 NFkB phosphorylation in ccRCC cells could be due to curcumin-induced suppression of IKK $\alpha$ activity. Likewise, the inhibitory effect of curcumin on STAT3 phosphorylation could involve suppressing receptor-associated Janus kinase(s) or the nonreceptor tyrosine kinase Src. Interestingly, Yonezawa et al. demonstrated the suppression of RCC cell growth by Src kinase inhibitor PP1 and that this was accompanied with decreased STAT3 activation. ${ }^{37}$ Our future studies will examine the role of IKK $\alpha$ and Src in mediating the growth suppressive effects of curcumin in ccRCC cells.

Recent studies suggested the potential of targeting $\mathrm{NF} \kappa \mathrm{B}$ and STAT3 signaling axes in ccRCC as novel therapeutic approaches. ${ }^{38,39}$ To this end, the proteasome inhibitor bortezomib induced apoptosis in ccRCC cells in a NFKB-dependent manner; however, just the suppression of NFאB was not sufficient to induce apoptosis in ccRCC cells, demonstrating the requirement of engaging additional signaling targets in inducing apoptosis in ccRCC cells. ${ }^{40}$ It is reasonable to conclude that the ability of curcumin to target two essential signaling arms in ccRCC, STAT3 and NFKB, might be the underlying basis of its pro-apoptotic effect.

Although curcumin is an effective and selective (i.e. targets tumor cells but not normal cells ${ }^{41,42}$ ) antitumor agent, its use in a clinical setting has been limited, primarily due to its well-documented poor pharmacokinetic profile. To overcome this limitation, novel approaches to enhancing the bioavailability of curcumin are now the focus of several studies. These include coadministration of curcumin and piperine (an inhibitor of glucuronidation), which resulted in a 2,000\% increase in bioavailability of curcumin. ${ }^{43}$ Another approach has led to the generation of nanoparticles of curcumin. Nanoparticle curcumin was effective at suppressing the growth of MCF-7 breast cancer cells, ${ }^{44}$ and at inhibiting NFKB activity and inducing apoptosis in human pancreatic tumor cell lines. ${ }^{45}$ Liposomal curcumin also was shown to be an effective anticancer agent in a pancreatic cancer xenograft model ${ }^{46,47}$ Additionally, complexing curcumin with micelles or phospholipids has proved to improve its bioavailability. ${ }^{48,49}$ Finally, synthetic curcumin analogs (e.g. EF-24, HO-3867) were reported to have increased bioavailability when compared to curcumin and are more effective than curcumin at suppressing tumor growth. ${ }^{50,51}$ Interestingly, following an intraperitoneal administration of HO-3867 in rats, the synthetic curcumin analog was detected in the blood, liver, stomach and kidney. ${ }^{51}$ 
Given the excellent safety profile of curcumin, and the recent efforts aimed at enhancing its bioavailability, we anticipate that clinical trials examining the efficacy of curcumin or its synthetic analogs in suppressing ccRCC tumorigenesis will be conducted.

\section{CONCLUSIONS}

We report a robust growth suppressive and proapoptotic in vitro effect of curcumin on ccRCC cells. Although in vitro findings do not necessarily translate into clinical care, if the growth suppressive effects of curcumin on ccRCC are validated in clinical trials, this therapeutic approach could complement existing therapies.

\section{Patient-Friendly Recap}

- Curcumin, a commonly used food additive in Southeast Asia, is known to inhibit the growth of several types of cancer cells in experimental settings.

- The authors studied whether curcumin could block growth and migration of malignant kidney cancer cells.

- The authors found that curcumin decreased the viability of kidney cancer cells as well as their ability to migrate.

- Given its few side effects, curcumin (or its synthetic analogs) could be considered for clinical trials aimed at deveoping novel therapies for kidney cancer.

\section{Conflicts of Interest}

None.

\section{References}

1. Motzer RJ, Bander NH, Nanus DM. Renal-cell carcinoma. N Engl J Med. 1996;335:865-75. CrossRef

2. Gore ME, Szczylik C, Porta C, et al. Safety and efficacy of sunitinib for metastatic renal-cell carcinoma: an expandedaccess trial. Lancet Oncol. 2009;10:757-63. CrossRef

3. Escudier B, Eisen T, Stadler WM, et al. Sorafenib in advanced clear-cell renal-cell carcinoma. N Engl J Med. 2007;356: 125-34. $\underline{\text { CrossRef }}$

4. Hudes GR, Carducci MA, Choueiri TK, et al. NCCN Task Force report: optimizing treatment of advanced renal cell carcinoma with molecular targeted therapy. J Natl Compr Canc Netw. 2011;9 Suppl 1:S1-29.

5. Kim WY, Kaelin WG. Role of VHL gene mutation in human cancer. J Clin Oncol. 2004;22:4991-5004. CrossRef
6. Ashida S, Furihata M, Tanimura M, et al. Molecular detection of von Hippel-Lindau gene mutations in urine and lymph node samples in patients with renal cell carcinoma: potential biomarkers for early diagnosis and postoperative metastatic status. J Urol. 2003;169:2089-93. CrossRef

7. Maxwell PH, Dachs GU, Gleadle JM, et al. Hypoxia-inducible factor-1 modulates gene expression in solid tumors and influences both angiogenesis and tumor growth. Proc Natl Acad Sci U S A. 1997;94:8104-9. CrossRef

8. Tomita Y, Bilim V, Kawasaki T, et al. Frequent expression of $\mathrm{Bcl}-2$ in renal-cell carcinomas carrying wild-type p53. Int $J$ Cancer. 1996;66:322-5.

9. Oya M, Takayanagi A, Horiguchi A, et al. Increased nuclear factor-kappa B activation is related to the tumor development of renal cell carcinoma. Carcinogenesis. 2003;24:377-84. CrossRef

10. Aggarwal BB, Kunnumakkara AB, Harikumar KB, et al. Signal transducer and activator of transcription-3, inflammation, and cancer: how intimate is the relationship? Ann N Y Acad Sci. 2009;1171:59-76. CrossRef

11. Al Zaid Siddiqui K, Turkson J. STAT3 as a target for inducing apoptosis in solid and hematological tumors. Cell Res. 2008;18:254-67. CrossRef

12. Huang S. Regulation of metastases by signal transducer and activator of transcription 3 signaling pathway: clinical implications. Clin Cancer Res. 2007;13:1362-6. CrossRef

13. Niu G, Wright KL, Huang M, et al. Constitutive Stat3 activity up-regulates VEGF expression and tumor angiogenesis. Oncogene. 2002;21:2000-8. CrossRef

14. Horiguchi A, Oya M, Shimada T, Uchida A, Marumo K, Murai M. Activation of signal transducer and activator of transcription 3 in renal cell carcinoma: a study of incidence and its association with pathological features and clinical outcome. J Urol. 2002;168:762-5. CrossRef

15. Guo C, Yang G, Khun K, et al. Activation of Stat3 in renal tumors. Am J Transl Res. 2009;1:283-90.

16. Singh S, Aggarwal BB. Activation of transcription factor NF-kappa B is suppressed by curcumin (diferuloylmethane) [corrected]. J Biol Chem. 1995;270:24995-5000. CrossRef

17. Bharti AC, Donato N, Aggarwal BB. Curcumin (diferuloylmethane) inhibits constitutive and IL-6-inducible STAT3 phosphorylation in human multiple myeloma cells. J Immunol. 2003;171:3863-71. CrossRef

18. Bangaru ML, Chen S, Woodliff J, Kansra S. Curcumin (diferuloylmethane) induces apoptosis and blocks migration of human medulloblastoma cells. Anticancer Res. 2010;30: 499-504.

19. Bobustuc GC, Smith JS, Maddipatla S, et al. MGMT inhibition restores ERalpha functional sensitivity to antiestrogen therapy. Mol Med. 2012;18:913-29. CrossRef

20. Kansra S, Yamagata S, Sneade L, Foster L, Ben Jonathan N. Differential effects of estrogen receptor antagonists on pituitary lactotroph proliferation and prolactin release. $\mathrm{Mol}$ Cell Endocrinol. 2005;239:27-36. CrossRef

21. Kansra S, Stoll SW, Johnson JL, Elder JT. Src family kinase inhibitors block amphiregulin-mediated autocrine ErbB signaling in normal human keratinocytes. Mol Pharmacol. 2005;67:1145-57. CrossRef

22. Nickerson ML, Jaeger E, Shi Y, et al. Improved identification of von Hippel-Lindau gene alterations in clear cell renal tumors. Clin Cancer Res. 2008;14:4726-34. CrossRef

23. Shinojima T, Oya M, Takayanagi A, Mizuno R, Shimizu N, 
Murai M. Renal cancer cells lacking hypoxia inducible factor (HIF)-1alpha expression maintain vascular endothelial growth factor expression through HIF-2alpha. Carcinogenesis. 2007;28:529-36. CrossRef

24. Wang YJ, Pan MH, Cheng AL, et al. Stability of curcumin in buffer solutions and characterization of its degradation products. J Pharm Biomed Anal. 1997;15:1867-76. CrossRef

25. Srinivasan M, Sudheer AR, Menon VP. Ferulic acid: therapeutic potential through its antioxidant property. J Clin Biochem Nutr. 2007;40:92-100. CrossRef

26. Sudheer AR, Muthukumaran S, Kalpana C, Srinivasan M, Menon VP. Protective effect of ferulic acid on nicotine-induced DNA damage and cellular changes in cultured rat peripheral blood lymphocytes: a comparison with $\mathrm{N}$-acetylcysteine. Toxicol In Vitro. 2007;21:576-85. CrossRef

27. Makni M, Chtourou Y, Fetoui H, Garoui EM, Boudawara T, Zeghal N. Evaluation of the antioxidant, anti-inflammatory and hepatoprotective properties of vanillin in carbon tetrachloridetreated rats. Eur J Pharmacol. 2011;668:133-9. CrossRef

28. Kanski J, Aksenova M, Stoyanova A, Butterfield DA. Ferulic acid antioxidant protection against hydroxyl and peroxyl radical oxidation in synaptosomal and neuronal cell culture systems in vitro: structure-activity studies. J Nutr Biochem. 2002;13:273-81. CrossRef

29. Tomita S, Ishibashi K, Hashimoto K, et al. Suppression of SOCS3 increases susceptibility of renal cell carcinoma to interferon-alpha. Cancer Sci. 2011;102:57-63. CrossRef

30. Tong QS, Zheng LD, Lu P, et al. Apoptosis-inducing effects of curcumin derivatives in human bladder cancer cells. Anticancer Drugs. 2006;17:279-87. CrossRef

31. Chiu J, Khan ZA, Farhangkhoee H, Chakrabarti S. Curcumin prevents diabetes-associated abnormalities in the kidneys by inhibiting p300 and nuclear factor-kappaB. Nutrition. 2009;25:964-72. CrossRef

32. Dhillon N, Aggarwal BB, Newman RA, et al. Phase II trial of curcumin in patients with advanced pancreatic cancer. Clin Cancer Res. 2008;14:4491-9. CrossRef

33. Karin M, Ben-Neriah Y. Phosphorylation meets ubiquitination: the control of NF-[kappa]B activity. Annu Rev Immunol. 2000;18:621-63. CrossRef

34. Sakaguchi M, Oka M, Iwasaki T, Fukami Y, Nishigori C. Role and regulation of STAT3 phosphorylation at Ser727 in melanocytes and melanoma cells. $J$ Invest Dermatol. 2012;132:1877-85. CrossRef

35. Sakurai H, Chiba H, Miyoshi H, Sugita T, Toriumi W. IkappaB kinases phosphorylate NF-kappaB p65 subunit on serine 536 in the transactivation domain. J Biol Chem. 1999;274: 30353-6. $\underline{\text { CrossRef }}$

36. Bharti AC, Donato N, Singh S, Aggarwal BB. Curcumin (diferuloylmethane) down-regulates the constitutive activation of nuclear factor-kappa B and IkappaBalpha kinase in human multiple myeloma cells, leading to suppression of proliferation and induction of apoptosis. Blood. 2003;101:1053-62. CrossRef

37. Yonezawa Y, Nagashima Y, Sato H, et al. Contribution of the Src family of kinases to the appearance of malignant phenotypes in renal cancer cells. Mol Carcinog. 2005;43: 188-97. $\underline{\text { CrossRef }}$
38. Sourbier C, Danilin S, Lindner V, et al. Targeting the nuclear factor-kappaB rescue pathway has promising future in human renal cell carcinoma therapy. Cancer Res. 2007;67:11668-76. CrossRef

39. Horiguchi A, Asano T, Kuroda K, et al. STAT3 inhibitor WP1066 as a novel therapeutic agent for renal cell carcinoma. Br J Cancer. 2010;102:1592-9. CrossRef

40. An J, Sun Y, Fisher M, Rettig MB. Maximal apoptosis of renal cell carcinoma by the proteasome inhibitor bortezomib is nuclear factor-kappaB dependent. Mol Cancer Ther. 2004;3:727-36.

41. Ohori H, Yamakoshi H, Tomizawa M, et al. Synthesis and biological analysis of new curcumin analogues bearing an enhanced potential for the medicinal treatment of cancer. Mol Cancer Ther. 2006;5:2563-71. CrossRef

42. Syng-Ai C, Kumari AL, Khar A. Effect of curcumin on normal and tumor cells: role of glutathione and bcl-2. Mol Cancer Ther. 2004;3:1101-8.

43. Shoba G, Joy D, Joseph T, Majeed M, Rajendran R, Srinivas PS. Influence of piperine on the pharmacokinetics of curcumin in animals and human volunteers. Planta Med. 1998;64:353-6. CrossRef

44. Kumar SS, Mahesh A, Mahadevan S, Mandal AB. Synthesis and characterization of curcumin loaded polymer/lipid based nanoparticles and evaluation of their antitumor effects on MCF-7 cells. Biochim Biophys Acta. 2014;1840:1913-22. CrossRef

45. Bisht S, Feldmann G, Soni S, et al. Polymeric nanoparticleencapsulated curcumin ("nanocurcumin"): a novel strategy for human cancer therapy. J Nanobiotechnology. 2007;5:3. CrossRef

46. Li L, Braiteh FS, Kurzrock R. Liposome-encapsulated curcumin: in vitro and in vivo effects on proliferation, apoptosis, signaling, and angiogenesis. Cancer. 2005;104:1322-31. CrossRef

47. Li L, Ahmed B, Mehta K, Kurzrock R. Liposomal curcumin with and without oxaliplatin: effects on cell growth, apoptosis, and angiogenesis in colorectal cancer. Mol Cancer Ther. 2007;6:1276-82. CrossRef

48. Ma Z, Shayeganpour A, Brocks DR, Lavasanifar A, Samuel J. High-performance liquid chromatography analysis of curcumin in rat plasma: application to pharmacokinetics of polymeric micellar formulation of curcumin. Biomed Chromatogr. 2007;21:546-52. CrossRef

49. Liu A, Lou H, Zhao L, Fan P. Validated LC/MS/MS assay for curcumin and tetrahydrocurcumin in rat plasma and application to pharmacokinetic study of phospholipid complex of curcumin. J Pharm Biomed Anal. 2006;40:720-7. CrossRef

50. Adams BK, Cai J, Armstrong J, et al. EF24, a novel synthetic curcumin analog, induces apoptosis in cancer cells via a redoxdependent mechanism. Anticancer Drugs. 2005;16:263-75. CrossRef

51. Dayton A, Selvendiran K, Kuppusamy ML, et al. Cellular uptake, retention and bioabsorption of HO-3867, a fluorinated curcumin analog with potential antitumor properties. Cancer Biol Ther. 2010;10:1027-32. CrossRef

(C) 2015 Aurora Health Care, Inc. 